\title{
Converted-wave moveout equation analysis
}

Nelson Ricardo Coelho Flores Zuniga* (IAG-USP), Eder Cassola Molina (IAG-USP), Renato Luiz Prado (IAG-USP)

Copyright 2016, SBGf - Sociedade Brasileira de Geofísica

Este texto foi preparado para a apresentação no VII Simpósio Brasileiro de Geofísica, Ouro Preto, 25 a 27 de outubro de 2016. Seu conteúdo foi revisado pelo Comitê Técnico do VII SimBGt, mas não necessariamente representa a opinião da SBGf ou de seus associados. É proibida a reprodução total ou parcial deste material para propósitos comerciais sem prévia autorização da SBGf.

\section{Abstract}

The velocity analysis of a seismic reflection event may be performed using the fitting between the observed curve and the calculated one. The challenge appears when the hyperbolic approximation cannot be used due to some characteristics which make a reflection event nonhyperbolic. To overcome this difficulty, several approximations were proposed.

Having the capacity of being as general as possible is very significant to an approximation in order to optimize some steps of seismic processing. Some approximations presented in this work showed to be very stable and brought better results than other known approximations.

For this, the approximation which presented the best results in previous works was analyzed aiming to understand its capacity of being more general than the others and its limitations. The complexity of the objective function and its quality of curve fitting for three models which differs from each other only for their stratigraphic characterization were analyzed.

The informations so obtained were important to define which kind of stratigraphic characterization (abnormal increase of velocity or abnormal decrease of velocity) generates more influence to the quality of the curve fitting.

\section{Introduction}

After Dix (1955) presented the hyperbola equation, many other approximations were proposed to characterize some peculiarities which generate nonhyperbolicity to a reflection event (Malovichko, 1978; Muir and Dellinger, 1985; Slotboom, 1990; Alkhalifah and Tsvankin, 1995; Ursin and Stovas, 2006; Blias, 2009). The comparison of these approximations was accomplished in few works (Aleixo and Schleicher, 2010; Golikov and Stovas, 2012; Zuniga et al., 2015).

Li (2001) proposed an equation which associates many conditions of nonhyperbolic behavior. This equation considers some parameters that have not been used together before. Yuan and Li (2002) tested the equation, and observed its efficiency to analyze converted waves in anisotropic media.
Some tests were accomplished and Li (2001) equation brought better results than the other existent equations, and for this reason it could be considered the most general approximation available for travel-time curve fitting (Zuniga et al., 2015).

In previous works, a significant limitation of this approximation was observed and it is associated to the fact that the velocity must always increase with the depth, and therefore the layer underlying always presents a higher velocity (Figure 1). For this reason, one or more layers with a velocity lower than the expected could bring a challenge for the curve fitting.

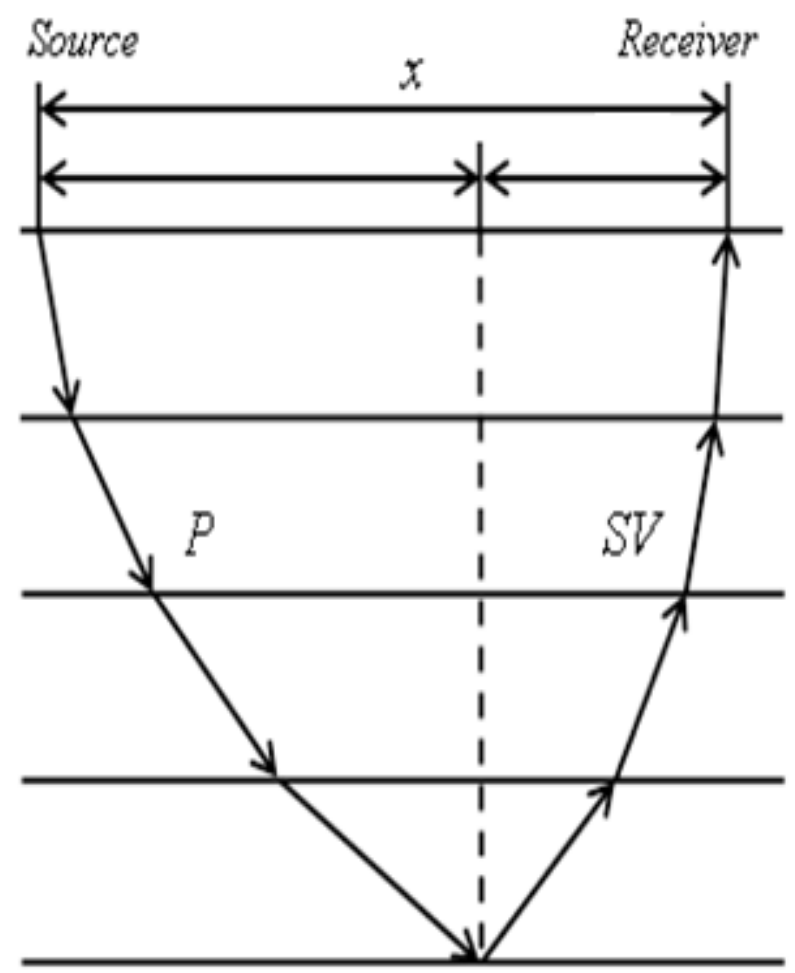

Figure 1: Converted wave ray tracing in VTI (media considering velocity always increases with depth.

Li (2001) approximation presented good results for models characterized by long offsets, wave conversion, using OBN technology, and strong vertical heterogeneity (Zuniga et al., 2015). Therefore, this study will be focused on the limitation of this approximation, and then to understand if it affects the behavior of the approximation, and how much. 


\section{Method}

Li (2001) equation uses a third parameter $(\gamma)$ and has the objective of control the behavior of a CP (Converted Point).

$$
t=\sqrt{t_{0}^{2}+\frac{x^{2}}{v^{2}}-\frac{(\gamma-1)}{w^{2}} \frac{(\gamma-1) x^{4}}{4 t_{0}^{2} v^{2}+(\gamma-1) x^{2}}}
$$

In this equation $t$ is the travel-time, $x$ is the offset, $v$ is the RMS velocity, $t_{0}$ is the time for zero-offset $\gamma$ is the ratio between squared stack velocity of $\mathrm{P}$ wave and squared velocity of converted wave, $\gamma_{2}$ is the ratio between stack velocity of $\mathbf{P}$ wave and stack velocity of $\mathbf{S}$ wave, $\gamma_{0}$ is the ratio between velocity of $P$ wave and velocity of $S$ wave which propagates in normal component, and $\gamma_{\text {eff }}$ is the ratio between squared $\gamma_{2}$ and $\gamma_{0}$.

$$
\begin{gathered}
\gamma=\frac{v_{p 2}^{2}}{v_{C 2}^{2}}=\frac{\gamma_{e f f}\left(1+\gamma_{0}\right)}{\left(1+\gamma_{e f f}\right)} \\
\gamma_{\text {eff }}=\frac{\gamma_{2}^{2}}{\gamma_{0}}
\end{gathered}
$$

The $\gamma$ parameter has intrinsically considered the anisotropic parameters (Thomsen, 1986). Li (2001) consider an isotropic medium for some tests, due to the fact that Thomsen anisotropic parameters help to control the behavior of RMS velocity for long offsets ( $\mathrm{Li}$ and Yuan, 2003).

To analyze the complexity of this equation in a broad category of models, the residual function maps were compared in order to understand the distribution of the minimum regions (Larsen, 1999; Kurt, 2007).

As this problem can be represented by three parameters it could be better treated as an inverse problem, and using an optimization criterion (Bokhonok, 2010).

The optimization algorithm used here was proposed by Nelder and Mead (1965), and the minimization method was the least squares.

The curve fitting was analyzed by the residual travel-time between the observed curve and calculated curve with $\mathrm{Li}$ (2001) equation for each model.

With these analyses, it is possible to understand if the mathematical and the geometric consideration observed in $\mathrm{Li}$ (2001) approximation would bring practical results affected by its assumption.

The models were generated by simplified velocity profiles (Leiderman et al., 2003) with a ray tracing algorithm. The first model was generated with a gradual velocity increasing with the depth. Model 2 has an abnormally high velocity layer between 1000 and 1200 meters. In that same interval, Model 3 presents an abnormally low velocity. Thus, it could be studied how the different velocity variation could interfere to perform the velocity analysis.

\section{Results}

Initially, the velocity profile was generated for each model and each wave reflection event (PP and PS) to characterize the complexity of each situation analyzed here (Figure 2).

The travel-time curves were generated for each model by the ray tracing method for PP and PS wave reflection events (Figure 3). It can be observed the abnormally high velocity interval of Model 2 presents a stronger variation on the ray tracing design than the abnormally low velocity interval of Model 3.

To understand how the complexity of the objective function varies with the different characteristics of the models, the residual function maps of $\mathrm{Li}$ (2001) approximation were generated for each reflection event and each model (Figure 4). Concerning to the complexity of objective function, it can be seen that the wave conversion affects the topography of the function much more than the model variation.

In Figure 5, it can be seen that there is no significant difference between the results obtained in Model 1 and Model 2 for both wave reflection events (PP and PS). It can be also seen that the results obtained in Model 3 are considerable different than the others, even for PP and PS reflection events.

\section{Conclusions}

There could be found no increase or decrease of complexity in the objective function capable of change the topography of the function when the characteristics of models in this work were varied.

Even with the ray tracing being more affected in Model 2, the greatest difference was generated by Model 3 , which brought much more difficult to the curve fitting.

The similarity of results observed for Model 1 and Model 2 shows the capacity of $\mathrm{Li}$ (2001) approximation of controlling the velocity increasing, even with a strong and abnormal velocity increasing.

The much more difficult curve fitting for Model 3 reflects a greater limitation of this approximation in the controlling a velocity decreasing, confirming the premises initially proposed.

In order to evaluate the real limitation of the approximation here investigated, it is necessary to test models which present stronger velocity decreases and more than one velocity decrease per model. 
(a)

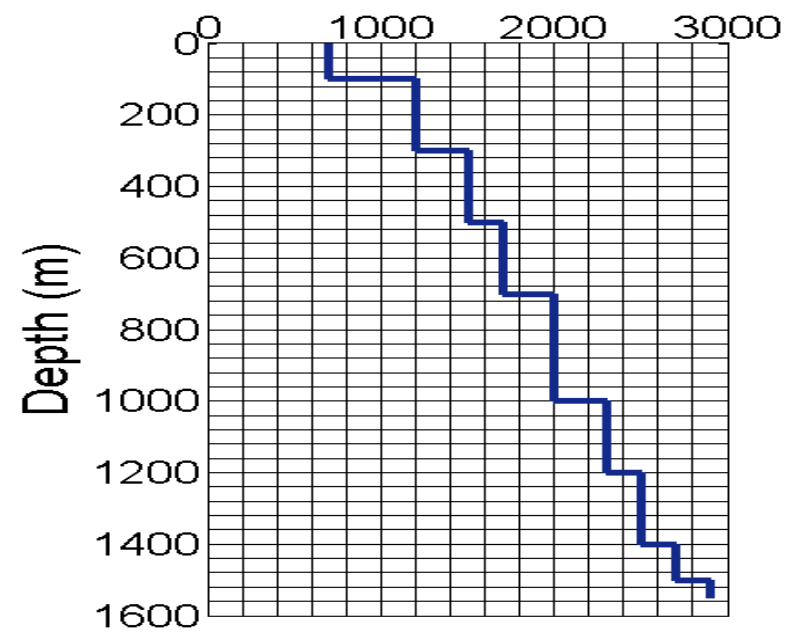

(c)

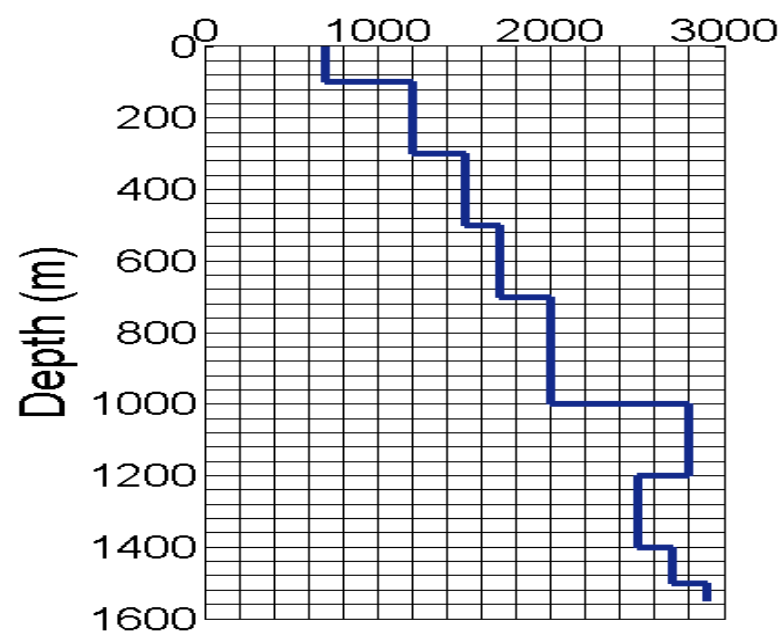

(e)

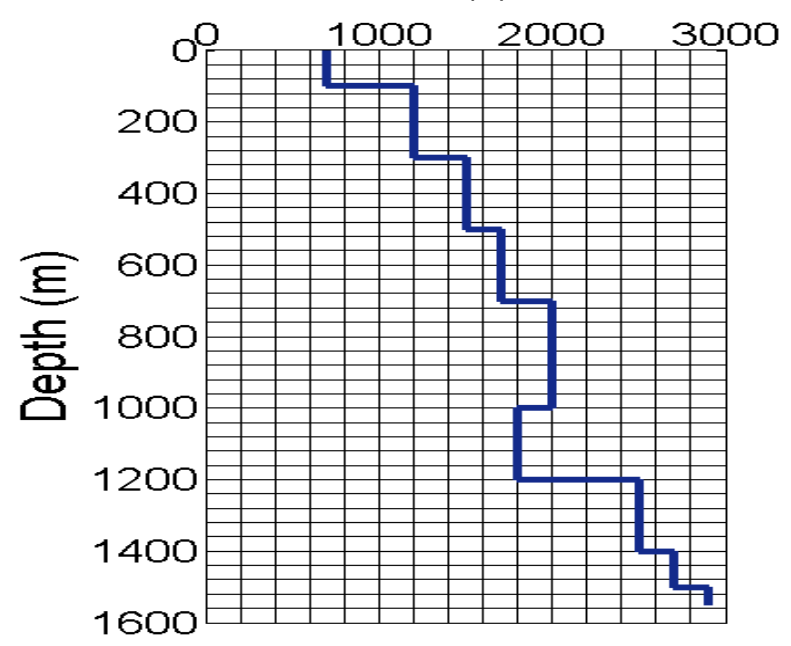

(b)

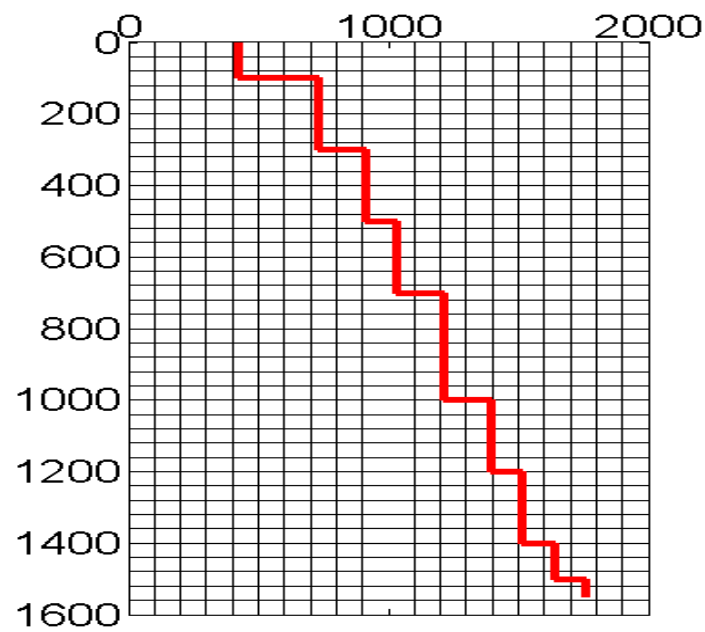

(d)

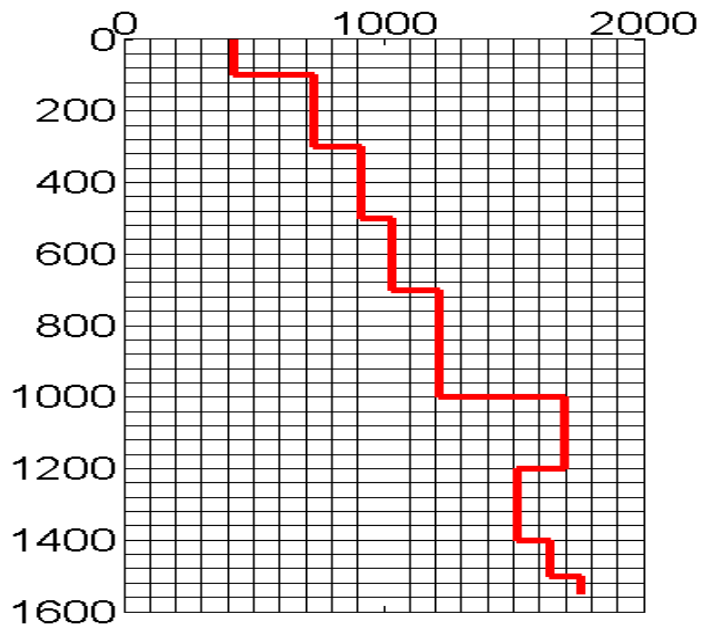

(f)

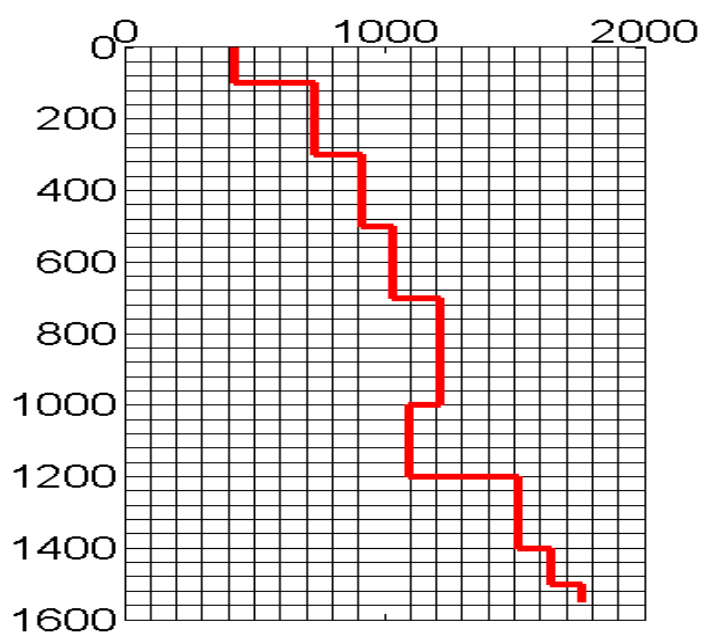

Figure 2: Velocity profile (in m/s) of (a) Vp of Model 1, (b) Vs of Model 1, (c) Vp of Model 2, (d) Vs of Model 2, (e) Vp of Model 3 , and (f) Vs of Model 3. Model 1 is the control analysis, with layers velocities increasing gradually with the depth. Model 2 presents an abnormally high velocity layer between 1000 and 1200 meters. Model 3 presents an abnormally low velocity layer between 1000 and 1200 meters. 
(a)

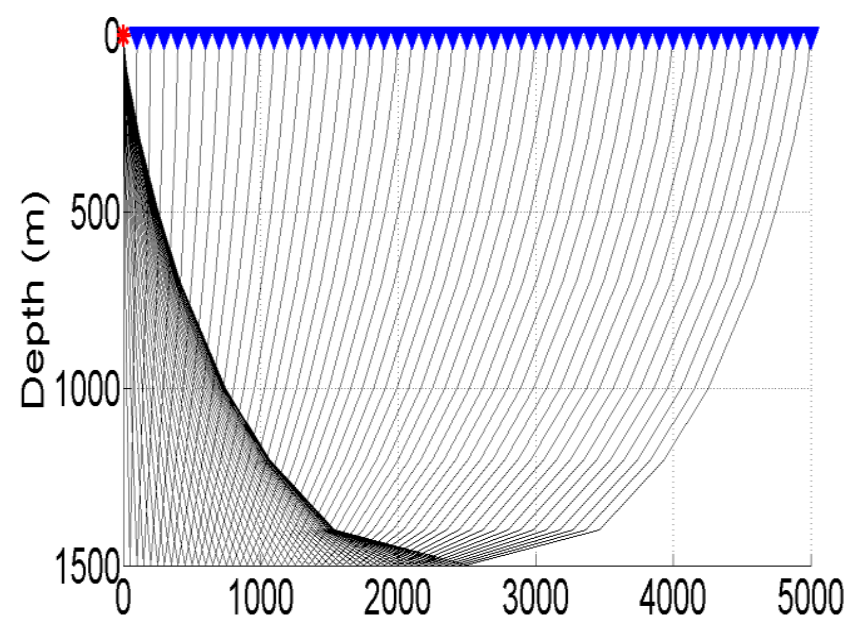

(c)

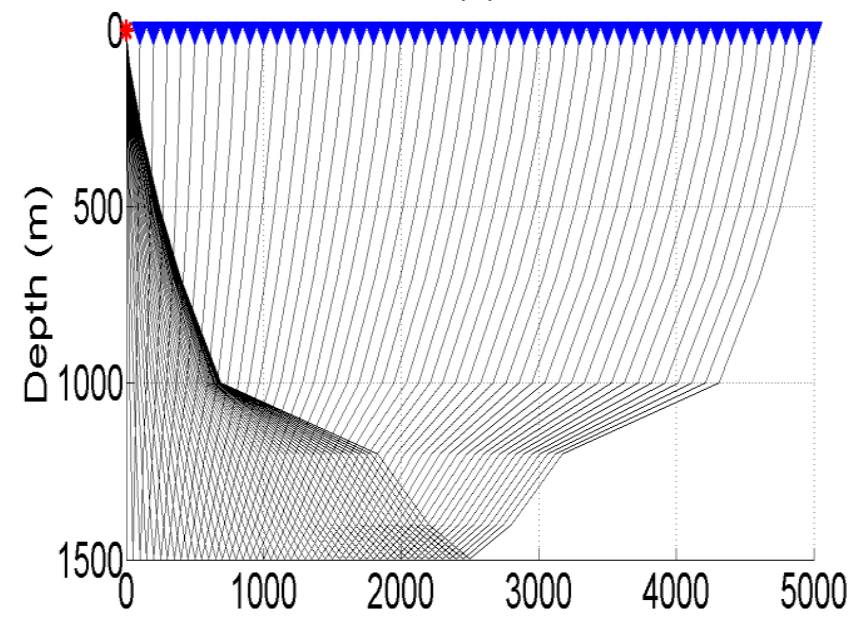

(e)

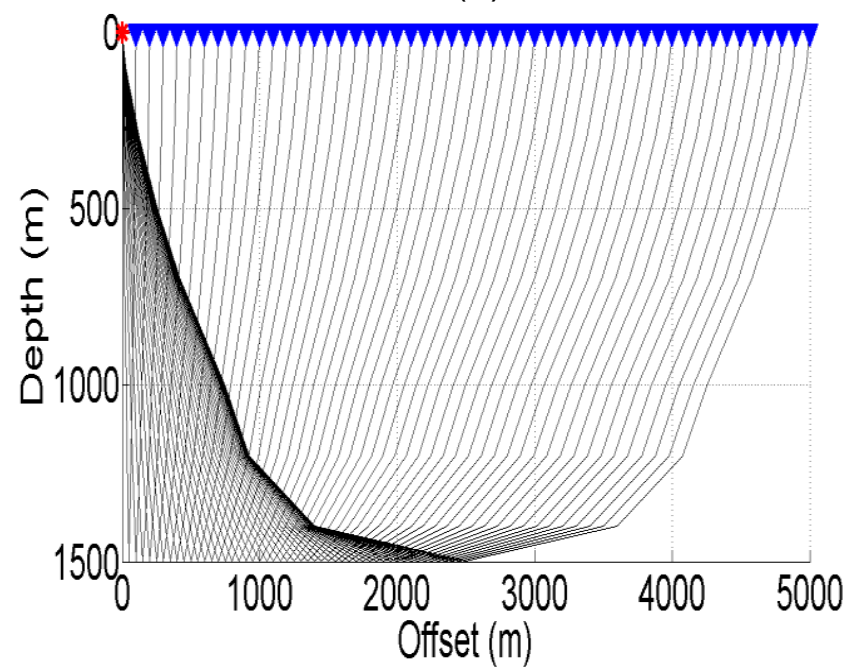

(b)

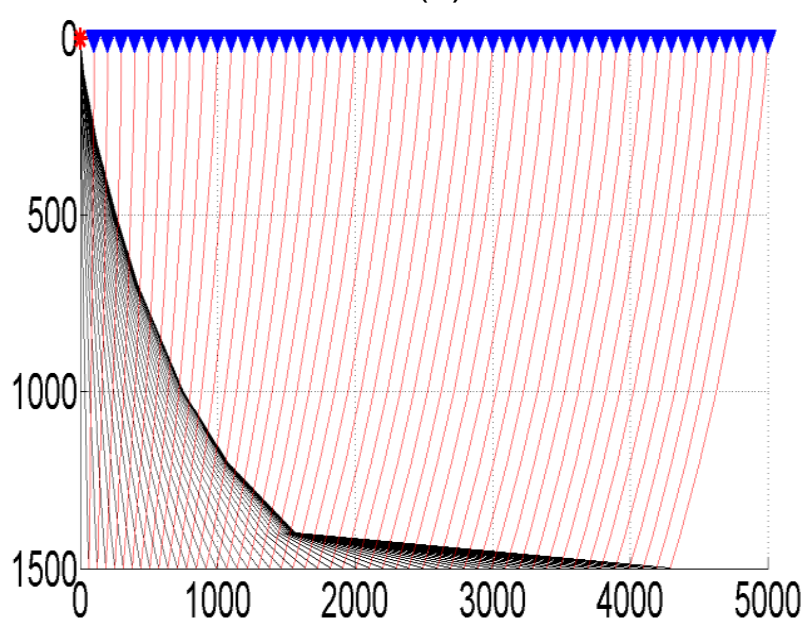

(d)

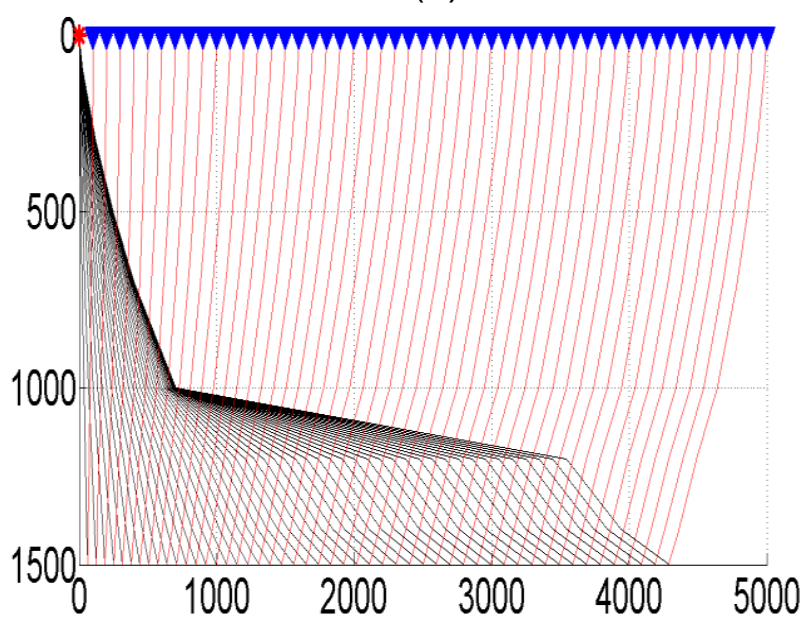

(f)

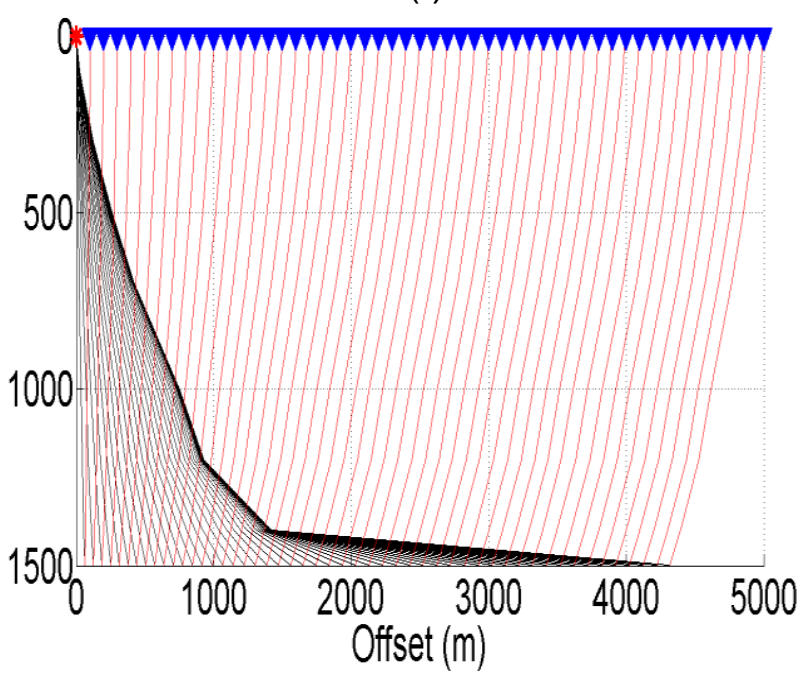

Figure 3: Ray tracing of (a) PP wave reflection event of Model 1, (b) PS wave reflection event of Model 1, (c) PP wave reflection event of Model 2, (d) PS wave reflection event of Model 2, (e) PP wave reflection event of Model 3, and (f) PS wave reflection event of Model 3. 
(a)

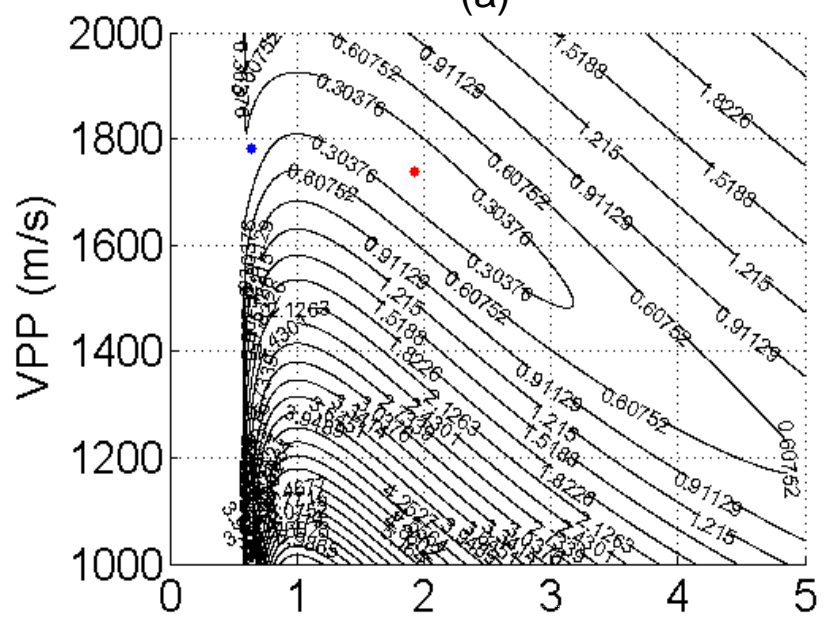

(c)

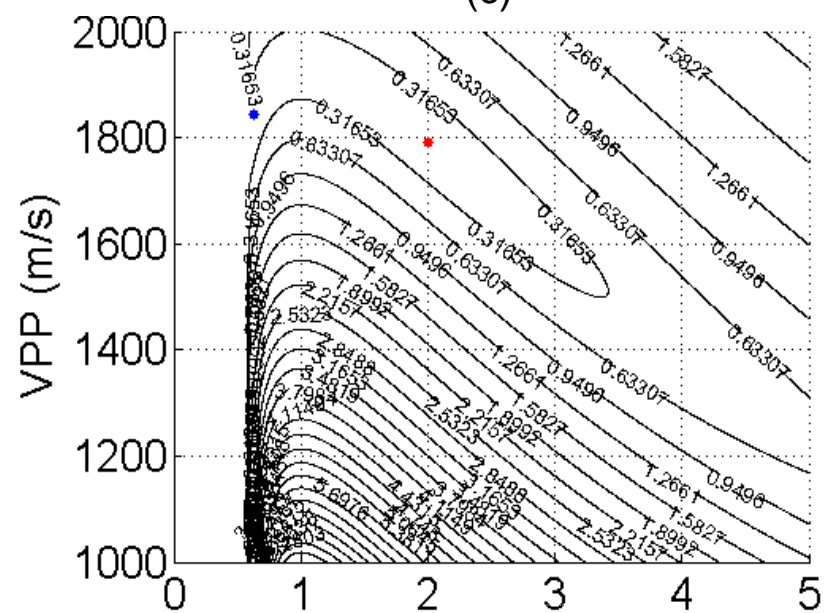

(e)

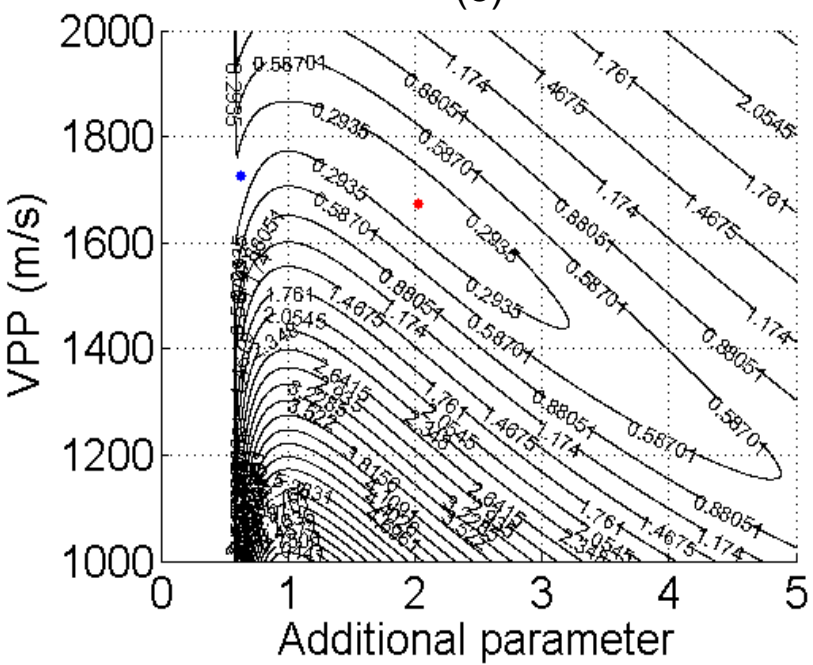

(b)

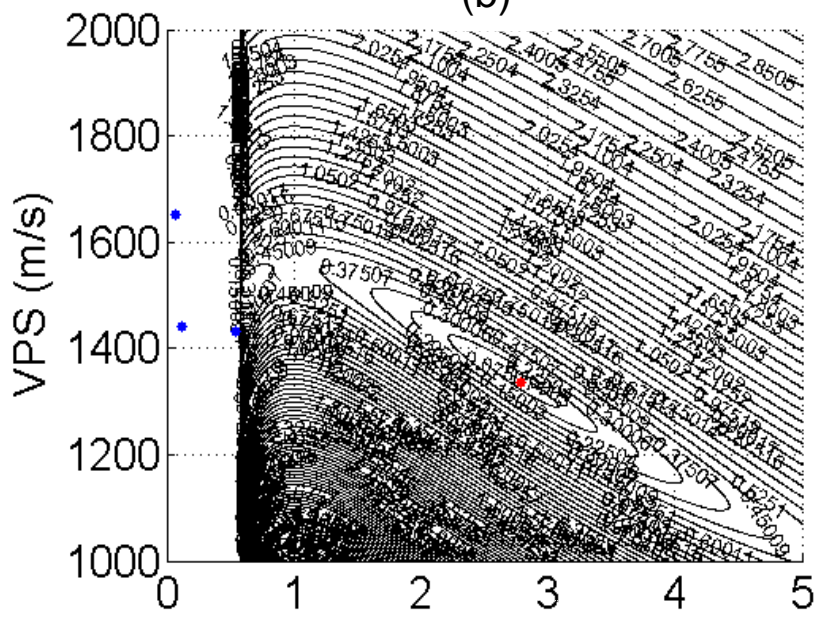

(d)

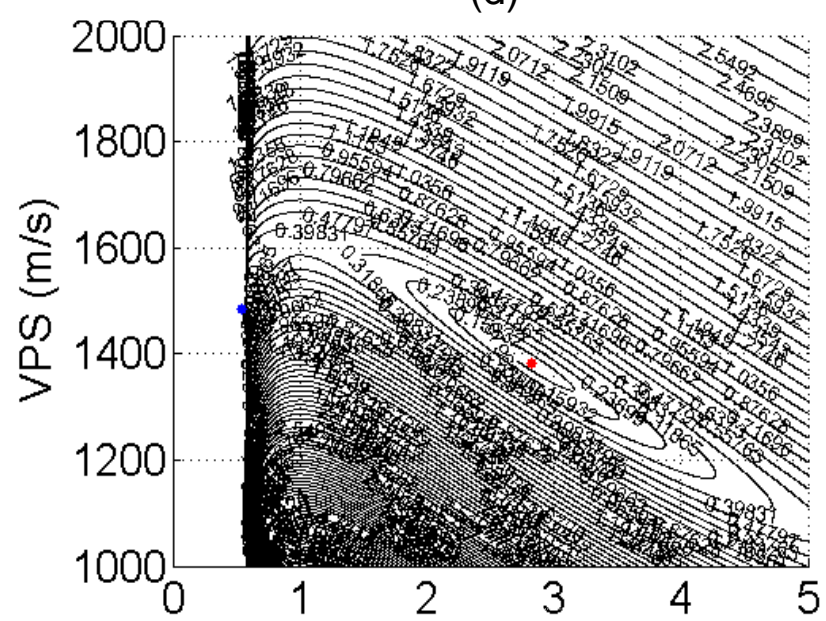

(f)

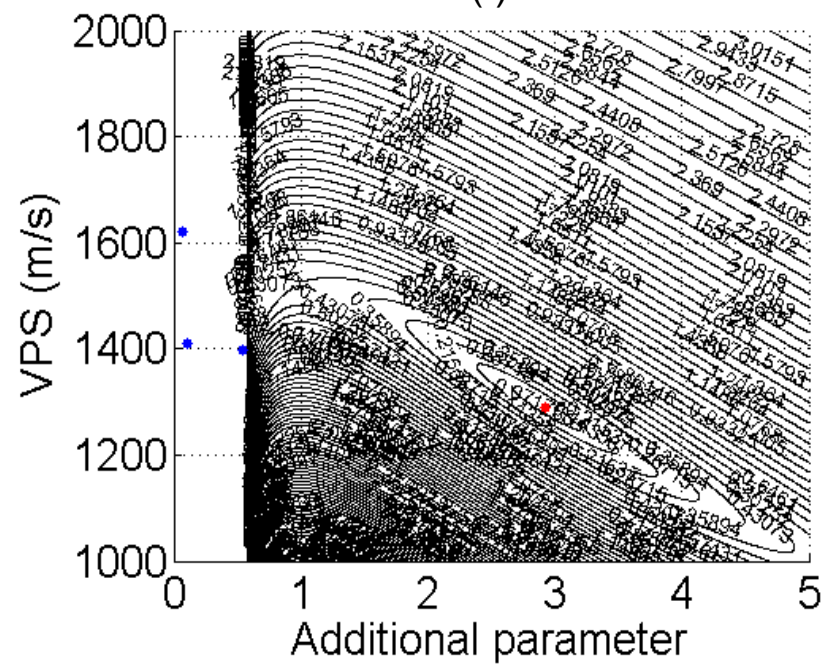

Figure 4: Residual function maps demonstrating the complexity of Li equation for (a) PP wave reflection event of Model 1, (b) PS wave reflection event of Model 1, (c) PP wave reflection event of Model 2, (d) PS wave reflection event of Model 2, (e) PP wave reflection event of Model 3, and (f) PS wave reflection event of Model 3. 


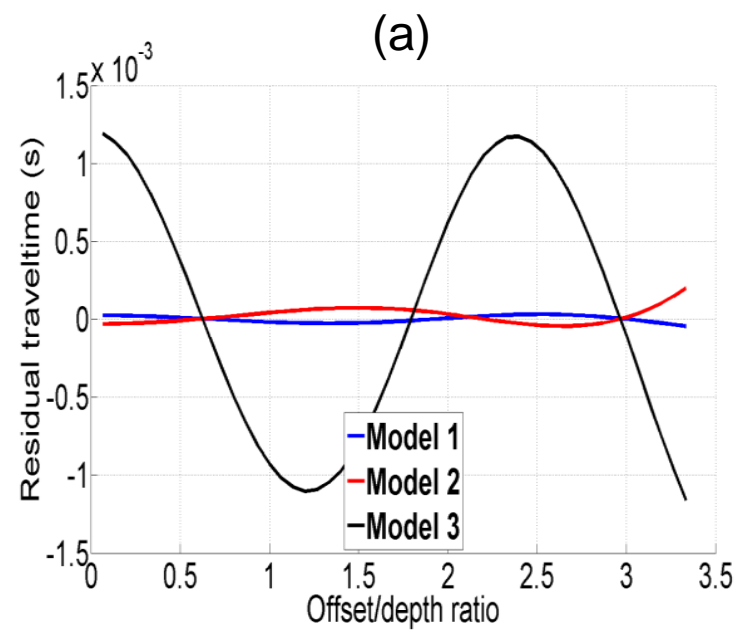

(b)

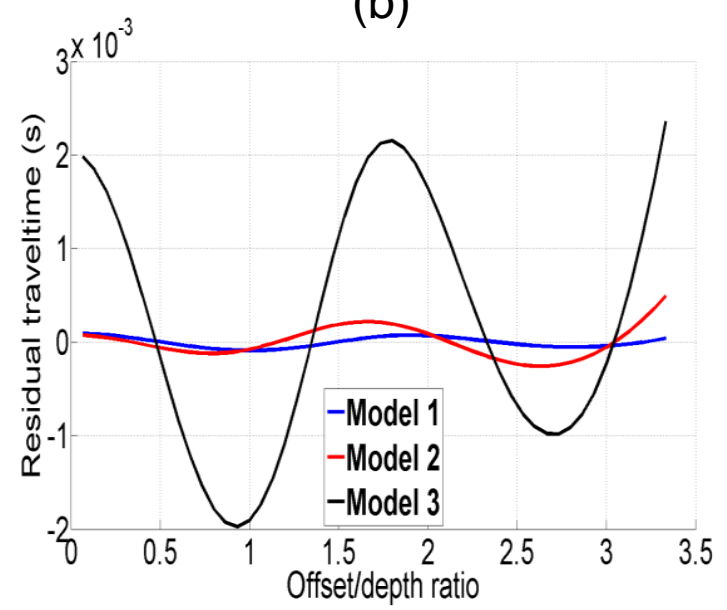

Figure 5: Residual travel time between observed and calculated curve with $\mathrm{Li}$ equation of (a) PP wave reflection event and (b) PS wave reflection event of each Model. blue curves represent Model 1, red curves represent Model 2 and black curves represent Model 3.

\section{References}

ALEIXO, R.; SCHLEICHER, J. Traveltime approximations for $q-P$ waves in vertical transversely isotropic media. Geophys. Prospect.Vol. 58, p. 191-201, 2010.

ALKHALIFAH, T.; TSVANKIN, I. Velocity analysis for transversely isotropic Media. Geophysics, v. 60, p. 1550-1566, 1995.

BLIAS, E. Long-offset NMO approximations for a layered VTI model: Model study. In: 79th Annual International Meeting: Society of Exploration Geophysics, 2009.

Expanded Abstract..., 2009.

BOKHONOK, O. Sísmica de reflexão rasa multicomponente: Aquisição e inversão de tempos de trânsito e amplitudes. Doctoral thesis. Universidade de São Paulo, 2010.

DIX, C. H. Seismic velocities from surface measurements: Geophysics, 20, p.68-86, 1955.
GOLIKOV, P.; STOVAS, A. Accuracy comparison of nonhyperbolic moveout approximations for qP-waves in VTI media. Journal of Geophysics and Engineering. Vol. 9, 428-432, 2012.

KURT, H. Joint inversion of AVA data for elastic parameters by bootstrapping. Computers \& Geosciences, v. 33, n. 3, p. 367-382, 2007.

LARSEN, J. A. AVO Inversion by Simultaneous P-P and P-S Inversion. 1999. (Master's Thesis) - University of Calgary Department of Geology and Geophysics, Calgary, 1999.

LEIDERMAN, R. et. al. Exemplo de modelagem sísmica dos modos PP e PS a partir de dados de poço e perfil litológico. $2^{\circ}$ Congresso Brasileiro de P\&D em Petróleo \& Gás, Expanded Abstract, 2003.

LI, X. Y.; YUAN, J. Converted-waves moveout and parameter estimation for transverse isotropy. 61st EAGE Conference, Expanded Abstract, v. 1, p. 4-35, 1999.

LI, X.Y.; YUAN, J. Converted wave imaging in inhomogeneous, anisotropic media: Part I. Parameter estimation. In: 63rdEAGE conference, Expanded Abstract, v. 1, p. 109, 2001.

LI, X. Y.; Converted-wave moveout analysis revisited: The search for a standard approach, 73rd Annual internat. Mtg. Soc. Expl. Geophysics, Expanded Abstract, p. 805-808, 2003.

MALOVICHKO, A. A. A new representation of the traveltime curve of reflected waves in horizontally layered media. Applied Geophysics (in Russian), v. 91, n. 1, p. 47-53, 1978.

MUIR, F.; DELLINGER, J. A practical anisotropic system, in SEP-44. Stanford Exploration Project, p. 55-58, 1985.

NELDER, J. A; MEAD, R. A simplex method for function minimization. The Computer Journal, v. 7, p. 308-313, 1965.

SLOTBOOM, R.T. Converted wave moveout estimation. In: 60 th Annual International Meeting: Society of Exploration Geophysics, 1990. Expanded Abstracts..., 1990. p. 1104-1106.

THOMSEN, L. Weak elastic anisotropy. Geophysics, v.51, p.1954-1966, 1986.

URSIN, B.; STOVAS, A. Traveltime approximations for a layered transversely isotropic medium. Geophysics, v. 71, p. 23-33, 2006.

YUAN, J.; LI, X. Y. Converted wave anisotropic parameter estimation from conversion point. In: 64rd EAGE conference, Expanded Abstract, v. 2, p. 253, 2002.

ZUNIGA, N. R. C. F.; BOKHONOK, O.; DIOGO, L. A. Comparison of nonhyperbolic travel-time approximations for multicomponent seismic data. In: 14th SBGf Congress, Expanded Abstract, p. 11761181, 2015. 